\title{
Influence of Training Programme on the Transfer Level of Agricultural Best Practices by Farmers: A Case of Gandini Irrigation Project, Kilifi County Kenya
}

\author{
Cornel Likale Ndombi, Johnbosco Kisimbii
}

*Corresponding Author: Cornel Likale Ndombi

\begin{abstract}
The purpose of training is to impart new knowledge and skills; and/or to refresh the knowledge that the trainees already have. Governments and non-governmental organizations spend much on training concentrating on agricultural best practices to impart farmers with knowledge and skills to utilize sustainable natural resource management practices in food security projects believing that training will improve performance and productivity. However, unsettling questions continue to be raised about the transfer of these agricultural best practices and the return in terms of performance and productivity on this investment. This study was aimed at answering research questions on the factors of training that seem to influence the level of transfer of agricultural best practices, with the following objectives: to find out how trainee attributes; trainer attributes; training design; and monitoring and evaluation influence level of transfer of agricultural best practices through hypotheses testing. The study was conducted through a descriptive research survey; case of Gandini Irrigation Project. Data was collected using questionnaires administered to 108 farmers (from a population of 149 farmers) who were randomly sampled using proportionate stratified method. Focus group discussion guides were administered to 6 men and 6 women. One checklist was used to collect secondary and primary data with the help of the members of project committee and project staff in charge. Percentages and tables were used to summarize, organize and present the data. To investigate whether a dependence relationship existed between two variables or whether the variables were statistically independent, Chisquare was used to test the hypotheses. The qualitative and quantitative data was triangulated for deeper understanding. Trainee's level of literacy, culture, trainers' ability to deliver feedback, instructional methods, participation by the trainees, training needs assessment and monitoring were found to have influence on the transfer of agricultural best practices. The study concluded that indeed the transfer of agricultural best practices is influenced by the trainee attributes, trainer attributes, training design and monitoring and evaluation and recommended that the training programmes to thoroughly consider training needs assessment; use of exchange programmes and establishment farmer field schools for exposure and exchange of ideas and experiences; and implementers to initiate and invest in Trainer of Trainees (ToT) approach. The study recommended further studies on the influence of culture and land tenancy on transfer of agricultural best practices.
\end{abstract}

Keywords: Training, Training transfer, Agricultural best practices, Trainee attributes, Trainer attributes, Training design, Motivation to train, Motivation to transfer.

\section{INTRODUCTION}

Investment in training activities has increased all over the world in recent years (Velada et al., 2007). Organizations in the United States alone spend billions on training each year (Salas et al., 2012; Seyler et al., 1998). Australian farmers have access to a wide variety of education and training sources (Kilpatrick, 2000). Those funding, running, facilitating and participating in training are involved because they expect the training to influence the behaviour of training participants, and hence impact on productivity, profitability and sustainability of projects. This is also true for the farming business. Education and training enhance farmers' ability and willingness to make successful changes to their management practice. The training program is generally only one of several factors which influence participants to make changes to their practice following the program. Training events are opportunities for interaction between participants and with expert trainers.

In the Philippines, extension practitioners have tried several approaches for disseminating new farming knowledge and other information to targeted communities. Because of the relatively low levels of education of farmers Rolaand et al. (2002) say, extension practitioners in the Philippines 
have developed more intensive interventions that engage farmers directly in the knowledge discovery process. The Indonesian experience holds lessons for development agencies and governments in developing countries, which are being encouraged to expand and promote the training approaches such as Farmer Field School (FFS) on a wider scale, making use of large volumes of foreign assistance funds and domestic fiscal resources (Feder, Murgai, \& Quizon, 2004). In Peruvian Andes potato farmers are trained and the yields were improved according to studies (Godtland et al., 2003).

Kenya largely depends on rain-fed agriculture for its food requirements, relying on the two main rain seasons namely the March-May long rains and October-December short rains. According to World Food Programme (WFP, 2014) about 80 percent of the land is arid or semi-arid. The national and county governments are collaborating with international and local NGOs to initiate projects with concerns with food security aimed at reaching Millennium Development Goal (MDG) One: Eradicate extreme poverty and hunger (World Bank, 2015). Food security projects are majorly concerned about stable and sustainable pillars of food security which are availability, accessibility and utilization (Action for Farming International, ACF, 2009). Their efforts are to see that there is enough food available in a long term continuous basis including when households face stress such as crop failure, fluctuation in food prices or seasonal changes in cash income or food production (Food and Agriculture Organization, FAO, 2011; 2013; 2005).

In Kenya for example, according to the Kilifi County financial plan (2014) the Ministry of Agriculture, Livestock and Fisheries estimated to spend KShs 259,753,754 during the 2014/15 financial year. Of this, KShs 75,209,638 was estimated for agriculture. Most of this was for rehabilitation of the irrigation projects, procurement of farm inputs, trainings and carrying out feasibility studies within the county. The county had estimated KShs 12,675,050 for the support of Kenya Red Cross Society (KRCS) through Gandini Irrigation Project (GIP), a food security project, the 2014/2015 financial year.

Building the capacity of the beneficiaries means that efforts are aimed at strengthening the skills and the knowledge of the communities so that they can take on responsibilities in managing the segments of the projects of the projects by themselves (Paul, 1987) by organizing the community into groups, educate and train them as most of them lack sufficient technical knowledge. According to Shoenfelt et al. (1991) the objectives of training are: knowledge attainment, adjusting attitudes, problem solving skills, interpersonal skills, participant acceptance, and knowledge retention. With these objectives a successful training results into trainees being able to learn new information; modify subsisting attitudes or beliefs; improve ability and skill in problem solving. A successful training also leads to higher, voluntary and willingness to participate during training. Further a successful training would improve the recall and utilization of the information and skills that were presented during training. The interaction between participants and facilitators which takes place during training time, before and after sessions and at breaks, allows individual farmers to compare their values and attitudes with group norms. Introduction of learning (farmer) oriented extension approaches is a potentially powerful tool in the transformation of negative perceptions, attitudes and behaviour among government extension workers towards traditional small-scale farmers (Dalsgaard et al., 2005). Farmers also undertake initiatives to acquire knowledge from other sources (published media, radio), as well as from their own experiences and experimentation (Feder, Murgai, \& Quizon, 2004).

The trainings that offered or facilitated by implementers of food security projects are concentrated on training of agricultural best practices. The main concerns in the pillars of agricultural best practices (Swanson, 2008) are technical and management skills; natural resource skills and knowledge; family nutrition, health and hygiene; and leadership and organizational skills. The technical and management skills are meant to enlighten the farmers to diversify from production of food staple crops to production of high-value crops and post-harvest handling; meeting product quality and learning how to use market information.

The natural resource management skills and knowledge emphasize on sustainable land management and conservation practices; sustainable water management and conservation practices (use of different water-efficient technologies, such as zaipits, basins, multi-storey gardening, furrows (in areas or seasons in which water is stressful). It also involves the use of water efficient crops, deficit irrigation and water harvesting techniques; river and watershed management practices); sustainable forestry, 
agro-forestry and wildlife management practices; biological management and biodiversity conservation practices; climate change and its implications for agricultural production systems. Family nutrition, health and hygiene is concerned with food processing and preservation; family nutrition, especially for infants and young children; family hygiene, including safe water handling and waste management; and family household management.

Lastly the farmers are also trained on leadership and organizational skills to influence and ease farmers getting organized into producer groups or other types of farm organizations to carry out specific activities, ranging from supplying high-value crops to urban markets.

Gandini Irrigation Project implemented by KRCS Malindi since January 2012 till to date has 149 farmers (households who before then depended on relief food in the previous years) working on a 300 acre piece of land in Gandini sub-location, Bungale location, in Marafa division, Magarini Sub-county of Kilifi County. The project has supported the primary land preparation; installation of irrigation system; installation of five greenhouses; procurement and distribution of farm implements, agrochemicals and planting materials (seeds, seedlings and cuttings). According to KRCS this had been done each year since the project was initiated tree years ago (KRCS, 2014). The project (on its fourth year of implementation) is implemented in Magarini sub-county, Marafa division, Bungale location in Gandini sub-location.

\section{Statement of The Problem}

Studies have shown that these projects (agricultural-food security projects) have performed poorly and attain lower scores. De Janvry (2010) said that agricultural investment projects have been faring poorly on a comparative basis, following misguided approaches such as the training-and-visit extension system, subsidized credit, and integrated rural development that have since been discontinued. Transfer of training for farmers is indicated in number of farmers adopting and practising new methods, acreage under new methods of cultivation, frequency of production, performance and organization of the farmer groups (cooperatives), crop yields, and income.

According the KRCS Kilifi County financial report (2014), Gandini Irrigation Project estimated a cost of Euro 30727/KShs 3,380,000 for capacity building and trainings. This was huge investment and looking at the allocation in the above trainings, scores in the August 2014 survey were much more below the expected. In a survey conducted in August 2014 (KRCS,2014), three years after the start of the project, most of the farmers were still using the traditional methods of agriculture; very few are continuously producing annually, the performance of the group is low, large tracks of land is underutilized. Only $13.6 \%$ of the farmers were practising irrigation, while $31.4 \%$ in areas where irrigation is not possible had initiated adaptive farming practices. The average annual income was estimated at KShs 4,520 for men and KShs 2,225 for females (against KShs 8,000 and KShs 4,000 respectively); while only $2.3 \%$ of the participants were members of functional cooperative societies (against 15\%). There was need for the study to find out why the level of transfer of the agricultural best practices (or training transfer) has been low yet many trainings had been conducted for the targeted farmers and influence of field training on the transfer of agricultural best practices in the food security component of the Magarini Integrated Project, the Gandini Irrigation Project.

The study was conducted in Kilifi County specifically focusing on Gandini Irrigation Project. The project just like some other food security projects was facing challenges of transfer of knowledge and skills acquired after training making it. Ideally the study ought to have been conducted in the whole county or even in country to get a bigger picture of the relationship of training factors and its transfer but it was due to limited resources that the findings in Gandini Irrigation Project were generalized for even other places with similar conditions.

The planned and estimated time for data collection coincided with the rainy season and busy schedule for most of these farmers given that they had other plots outside the project sites. Another limitation was logistical challenge. The public service vehicles that reached the area on average reached the area almost in the mid day in some days. The research project was based on the assumption that the respondents provided the reliably relevant information. It also assumed that the community that was sampled was a representative of the rest of the population. 


\section{Purpose OF THE STUdy}

The purpose of the study was to study influence of training on the transfer level of agricultural best practices by farmers in Gandini Irrigation project, Kilifi County Kenya.

\section{OBJECTIVES OF THE STUdY}

The objectives of this study were:

1. To determine the extent to which trainee attributes in a training programme influence the level of transfer of agriculture best practices by farmers in Gandini Irrigation Project

2. To find out how trainer attributes in a training programme influence the level of transfer of agricultural best practices by farmers in Gandini Irrigation Project

3. To explore the influence of the training design in a training programme on the level of transfer of agriculture best practices by farmers in Gandini Irrigation Project

4. To assess how monitoring and evaluation in a training programme influences the level of transfer of agriculture best practices by farmers in Gandini Irrigation Project

\section{RESEARCH QUESTIONS}

The study sought to answer the following research questions:

1. How do trainee attributes in a training programme influence the level of transfer of agricultural best practices in Gandini Irrigation Project?

2. How do trainer attributes in a training programme influence the level of transfer of the agricultural best practices in Gandini Irrigation Project?

3. How does training design in a training programme influence the level of transfer of the agricultural best practices in Gandini Irrigation Project?

4. How does monitoring and evaluation in a training programme influence the level of transfer of the agricultural best practices in Gandini Irrigation Project?

\section{RESEARCH HYPOTHESES}

The study tested the following null hypotheses:

1. $\mathbf{H}_{\mathbf{0}}$ : The trainee attributes in a training programme influence the level of transfer of agricultural best practices in Gandini Irrigation Project

2. $\mathbf{H}_{\mathbf{0}}$ : Trainer attributes in a training programme influence the level of transfer of the agricultural best practices in Gandini Irrigation Project

3. $\mathbf{H}_{\mathbf{0}}$ : Training design in a training programme influences the level of transfer of the agricultural best practices in Gandini Irrigation Project

4. $\mathbf{H}_{\mathbf{0}}$ : Monitoring and evaluation in a training programme influence the level of transfer of the agricultural best practices in Gandini Irrigation Project

\section{LITERATURE REVIEW}

\subsection{Concept of Training}

Building the capacity of the communities according to Paul (1987) means that efforts are aimed at strengthening the skills and the knowledge of the communities so that they can take on responsibilities in managing the segments of the projects of the projects by themselves. This means that the success of even farmers in an agricultural project is pegged on their capacity. Capacity refers to training, skills and capabilities of farmers and groups. In study conducted in Meru, Kenya by Davis et al. (2004) informants viewed trainings as very important to success for dairy goat groups in dissemination.

Many organizations spend much money on training, believing that training will improve performance and hence the organizational productivity. In 1997, organizations with more than one hundred employees were estimated to have spent $\$ 58.6$ billion in direct costs on formal training. However, unsettling questions continue to be raised about the return on this investment. In other words, training 
is useless if it cannot be translated into performance (Yamhill \& McLean, 2001). Nikandrou et al. (2009) found that with high investments in and allocation of resources to training, the need for justifying training effectiveness and documenting that employees (for this case the farmers) can transfer and use the skills learnt to their work environment has accelerated. Therefore, what counts in every training program is whether the participants are able to transfer and apply the skills they learn to their work. In review and analysis of literature by Ford \& Weinstein (1997) transfer of training is the degree to which trainees effectively apply the knowledge, skills, and attitudes gained in the training context to the job. The success of a training programme is seen in its transfer.

A training design according to Curry, Caplan \& Knuppel (1994) consists of the following sequence: conduct needs assessment, develop training objectives, design curriculum, design and select training methods, design evaluation approach, conduct training, and measure results.

Studies distinguish three categories of factors influencing training transfer as: factors concerning the trainee; factors concerning the training and the planning of the training, training methods, training place and equipment. For the purpose of this study, monitoring and evaluation was treated as a different entity as Salas \& Cannon-Bowers (2001); and Kirkpatrick (1979) found out that monitoring and evaluation is also another important factor in transfer, retention and thus transfer of the knowledge and skills acquired.

This study intended to study four factors of training that seem to affect the farmers' level of transfer of the agricultural best practices that they are trained namely: trainee attributes, trainer attributes, training design and monitoring and evaluation. These factors are intertwined.

\subsection{Trainee Attributes and Transfer Level of Agricultural Best Practices}

Studies have found the following aspects of trainees have a hand in the trainees' ability to learn, transfer and eventually adopt the practices: age, motivation, gender, level of education and interest.

\subsubsection{Motivation of the Trainee}

In a training process there are two types of motivation: training motivation and motivation to transfer. In order for the person to acquire and transfer the knowledge and skills acquired through training, he must have both. Training motivation spurs transfer motivation. Motivation to transfer according to Seyler et al., (1998) is an intended effort towards utilizing the skills and knowledge acquired from a training atmosphere to real work situation.

Nikandrou et al. (2009) found that the person who intrinsically makes the decision to participate in a training program is an important factor in the training transfer process. In their case, the employees (or trainees) decided to participate due to their low level of job satisfaction and played an active role in the content of their training. Colquitt et al. (2000) in their training meta-analysis found out that motivation to learn related positively with skill acquisition, reactions and transfer of training. If farmers perceive that what they learn is relevant to their goal (what they need to know) or an intervention has met their expectations and fulfilled their need, they will be more motivated to transfer learning into performance. This relates to employees training and their jobs in a study by Yamhill \& McLean (2001). In Expectancy theory of motivation by Vroom suggested that individuals are more motivated if they believe that their efforts will lead to enhanced performance. More successful learners would be expected to feel better able to perform, and therefore, more motivated to transfer.

\subsubsection{Age of the Trainee}

Learning happens at all ages, although it does decline somewhat with age. Numerous studies have documented that the level of training falls with the age of the worker. Different types of training vary by the age of the worker.

In his study Richardson (2004) found out that generally, workers under the age of 25 are those most likely to receive this hands-on training - as over $80 \%$ of young workers do although that almost half of the oldest age group of workers still learn skills from their co-workers. Kirkpatrick (1979) agrees that age affects the mastery orientation of the trainee in the recall and the application of the acquired knowledge. Older workers have a lower motivation, learning, and post-training efficacy (Salas \& Cannon-Bowers, 2001). In a study conducted by Kubeck et al. (1996) concluded that older adults 
have less mastery of the training content than younger adults, and they require more time to cover the training material.

Trainees must have the ability to retain the knowledge instilled during the training program to facilitate the transfer process. Similar to cognitive ability, Velada et al. (2007) define training retention as the degree to which trainees retain the content after training is completed. Van Gerven et al. (2002) in their study found out that elderly spent more time on training and experienced higher levels of cognitive load relative to the young, which strongly supported the view that working memory plays an essential role in learning new skills; and that elderly participants are disproportionally favored when studying worked examples. Age has a hand in physical strength of individuals. Younger individuals have generally stronger than the elderly.

\subsection{Trainee Literacy Level}

Barton (2000) defines literacy as being able to read, decode printed knowledge word, or comprehend what is written. It also means being well-informed and educated. He implies being able to use printed and written information to function in society, to achieve one's goals, and to develop one's knowledge and potential and that it is related to years of education: the higher the education level, the higher the average literacy score. Among forms of literacy at the level of farmers, prose literacy (understanding and using information from texts) and quantitative literacy (being able to apply mathematical operations) are very important.

Those with the least education (less than year 12) systematically report receiving less of the main forms of training. The more formal the training, the more it is focused on those with more education, and the less do those with the least education benefit (Richardson, 2004).

\subsection{Trainer Attributes and Transfer Level of Agricultural Best Practices}

These are distinguishing characteristics of an individual that can influence learner's learning and transfer of knowledge and skills. They are expressiveness and organization, teaching abilities and feedback.

\subsubsection{Expressiveness and Organization of the Trainer}

Effectiveness of trainer's delivery of a lecture is dependent on the expressiveness (appropriate vocal intonations and fluency) of the verbal presentation and the organization of the textual content of the lecture. Expressiveness and organization influence the recall and problem solving (Towler \& Dipboye, 2001). Trainees respond more affirmatively to an expressive and organized lecture and are better able to remember and apply what they learn compared to a disorganized lecture delivered inexpressively. An organized trainer provides simplified and elaborative content which is easy to follow.

\subsubsection{Teaching Abilities of the Trainer}

Further, Towler \& Dipboye (2001) say that the instructor's sensitivity to the cultural differences that students may face during the training is critical for successful training. In addition to instructor's sensitivity and respect for the trainees, Boendermaker et al. (2003) found that the instructor should also be critical of the trainee learning process. Following these researchers, the current study included the language and relevancy used under this attribute. The trainer should be relevant with his or her examples and the language that the trainees understand.

In the study by Boendermaker et al., (2000) teaching knowledge is about knowing when and how to use various teaching methods. They mentioned that teaching skills are about the best a trainer uses the knowledge, giving feedback, being observant, encouraging and being able to communicate and handle conflicts.

Burke\& Hutchins (2008) described trainer's characteristics such as knowledge of the subject matter, professional experience, and knowledge of teaching principles, flexibility to the subject matter, adaptability to each learner's experience, and knowledge of learning style and teaching principles needs as supporters of training transfer. The trainer needs to enjoy self-confidence as well as confidence with the trainees-enjoys and learns from the training process since it provides the opportunity for the trainer to recognize that different people have different styles of learning and helps them to learn how to train in future (Schwartz, 1988). 
Self confidence also comes when the trainer has mastery of the subject and she or he is equipped with the training knowledge. Boendermaker et al. (2000) add enthusiasm, flexibility and patience as personal traits.

\subsubsection{Feedback by the Trainer to the Trainee}

Feedback is a vital aspect of teaching and learning. Feedback can be vertical or horizontal; positive or negative. Feedback is defined by Clynes et al (2008) as an interactive process which aims to provide learners with insight into their performance. In as much as Boendermaker et al., (2003) categorize giving feedback as a trainer attribute, Salas \& Cannon-Bowers (2001) say that it should be during and after the training. Feedback is essential for the learners' growth; and significantly enhances communication and interpersonal skills of the trainers. It gives direction and boosts confidence while increasing motivation and self-esteem of the trainer. Best feedback is true, greatly specific, and explanatory of what actually occurred.

\subsection{Training Design and the Transfer Level of Agricultural Best Practices}

The effect of training design on transfer of training has been studied by numerous researchers and according to Lim (2000) is because it is believed to be one of the most important constructs affecting training transfer. In his study he found that the two categories of training design variables were derived from many studies on transfer of training: instructional design and instructional method. Because there is no single method to deliver training, researchers continue to address how to best present targeted information to trainees (Salas \& Cannon-Bowers, 2001). There is a science of training that shows that there is a right way and a wrong way to design, deliver, and implement a training program (Salas et al., 2012).

\subsubsection{The Content}

The content of the training program should be relevant either to the immediate trainee's work needs or to future career needs. A number of studies have suggested that the issue of relevance of knowledge in training is of critical value in determining transfer. Thus, not only instructional design but also the relevance of instructional content is important and necessary components of conditions supporting training transfer (Yamnill \& McLean, 2001).

Nikandrou et al., (2009) say that training design must concentrate on applying learning in different contexts. From what they found out about trainees in their study their participation of increased when they realized that the training was useful to their career. Trainees are more likely to transfer the training content to the work context when they perceive that the training program was designed and delivered in such a way that maximizes the trainee's ability to transfer the training to the job (Velada et al., 2007).

\subsubsection{Instructional Methods}

Recognizing learning style differences between workers, and between supervisors and trainees, can help to facilitate the learning and transfer process. Effective trainers are able to recognize learning differences, and to develop training approaches that emphasize a variety of methods. In this way, they can tap into predominant learning styles and help workers to use their less developed learning patterns. Parker's training cycle (Curry, Caplan, \& Knuppel, 1994) and Nikandrou et al., (2009) mention training methods as important in training design in the transfer of training.

Several effective instructional methods for effective training transfer: use of many different examples in various contexts and use of analogies. The use of diverse instructional methods is considered an important strategy for training design that leads to successful training transfer. By providing learning experiences in different ways, the trainees can master the training content conceptually and experientially. When a variety of relevant training stimuli are employed in the training content; and when trainees are taught the general rules and theoretical principles that underlie the training content there results a positive influence training transfer.

Collaborative learning (Salas \& Cannon-Bowers, 2001) is where trainees are trained in groups, but not necessarily to perform a team task. The idea is that there are features of group interaction that benefit the learning process. In order to address all the training objectives and to facilitate the 
knowledge acquisition as well as behaviour change, different training methods were used including lecture, discussion, simulations (e.g. role play) and audiovisuals (Velada et al., 2007).

Lim (2000) concludes that the use of diverse instructional methods is considered an important strategy for training design that leads to successful training transfer. By providing learning experiences in different ways, the trainees can master the training content conceptually and experientially. The fact that Van Gerven et al., (2002) concluded that elderly participants are disproportionally favored when studying worked examples can give a clue on what method trainers can adopt during training.

\subsubsection{Participation of the Trainee}

Training design should allow cumulative learning, participation of trainees during the training and even after training e.g. during decision making. Participation (which is much related in adult literacy) ensures ownership and innovation during the training and its transfer as Pretty (1995) notes. He further gives examples of energizers, work sharing, group formation and presentation as techniques for participatory learning. Answering and asking question is a participatory way in a training session.

Stewart et al., (2010) agree that there is a link between demotivation and participation (of high skilled workers. In their survey they tried to answer questions concerning the extent which training helped workers exert greater influence over different levels of decision-making at work and whether they would welcome more training that might help them to exert greater influence over these different levels of decision-making. Burke \& Hutchins (2008) found out in their study that training professionals reported using interactive exercises to encourage participation and making training content relevant as those strategies used in the design that best support transfer.

\subsection{Monitoring and Evaluation and the Transfer Level of Agricultural Best Practices}

Monitoring and evaluation (M\&E) in training is a process that takes place prior, during and after the training. $M \& E$ is an integral part of the training program. It involves assessment prior, during after and post-training. Timely and reliable M\&E provides information to: support project implementation; contribute to learning and knowledge sharing; uphold compliance; provides opportunities for stakeholders' feedback; and promote and celebrate achievements (IFRC \& RCS, 2011).

\subsubsection{Needs Assessment Prior to the Training}

In training (Salas \& Cannon-Bowers, 2001), monitoring and evaluation it not only about routine observation and justifying the cost and benefit of the program but it involves what happens or the situation before the training, events that take place before, during and after the training since each is as important as the other. Conducting a training needs analysis is one of the most important steps in training development. It focuses on the process of deciding who and what should be trained. This step specifies the learning objectives, which in turn shape the design and delivery of training, as well as the process of criterion development. Unfortunately, many training programs fail to reach their goals because of organizational constraints and conflicts, which could have been identified and ameliorated solved before training was implemented Salas \& Cannon-Bowers (2001). When training need is indicated by more than one assessment method, there is a greater chance that training can have an impact in the workplace. Examining trainee characteristics, such as skill and motivation levels according to Stewart (1986) can help provide early information to determine when training can aid in solving a performance problem. Thorough training needs assessment at the individual participant level seems important to ensure the success of training transfer as well as the quality of training (Lim, 2000).

\subsubsection{Monitoring the Trainee Progress}

Monitoring goes hand in hand with feedback after the training, that is, during the implementation of the practices (knowledge and skills) learned during the training. Monitoring is a routine activity of observing collecting and analyzing information to track progress against the set plans and check compliance to established standards (IFRC \& RCS, 2011). During monitoring the learners' newly learned skills and knowledge are reinforced. From the definition of M\&E, with timely, close and consistence monitoring new practices learned can be upheld by ensuring compliance on the part of the trainees. 


\subsubsection{Post-Training Evaluation}

Carrying out a post-training evaluation involves carrying out an assessment after the training, as systematic and objective as possible, of completed training programme in its totality (its design, implementation and results). The aim is to determine the relevance and fulfilment of objectives, developmental efficiency, effectiveness, impact and sustainability. An evaluation should provide information that is credible and useful, enabling the incorporation of lessons learned into the decisionmaking process. Burke \& Hutchins (2008) show need for a specific measurement tool following the training. Salas et al., (2012) say that evaluation allows organizations to continue conducting training that works and to modify or discontinue training that does not work. IFRC \& RCS (2011) puts it clear that the best evaluation is the one that involves as key stakeholders as much as possible. In this context it means the trainees, trainers and the organizers of the training, partners, donors, etc. Participation helps to ensure different perspectives are taken into account, and it reinforces learning from and ownership of the evaluation findings.

\section{CONCEPTUAl Framework}

\section{Independent Variables}
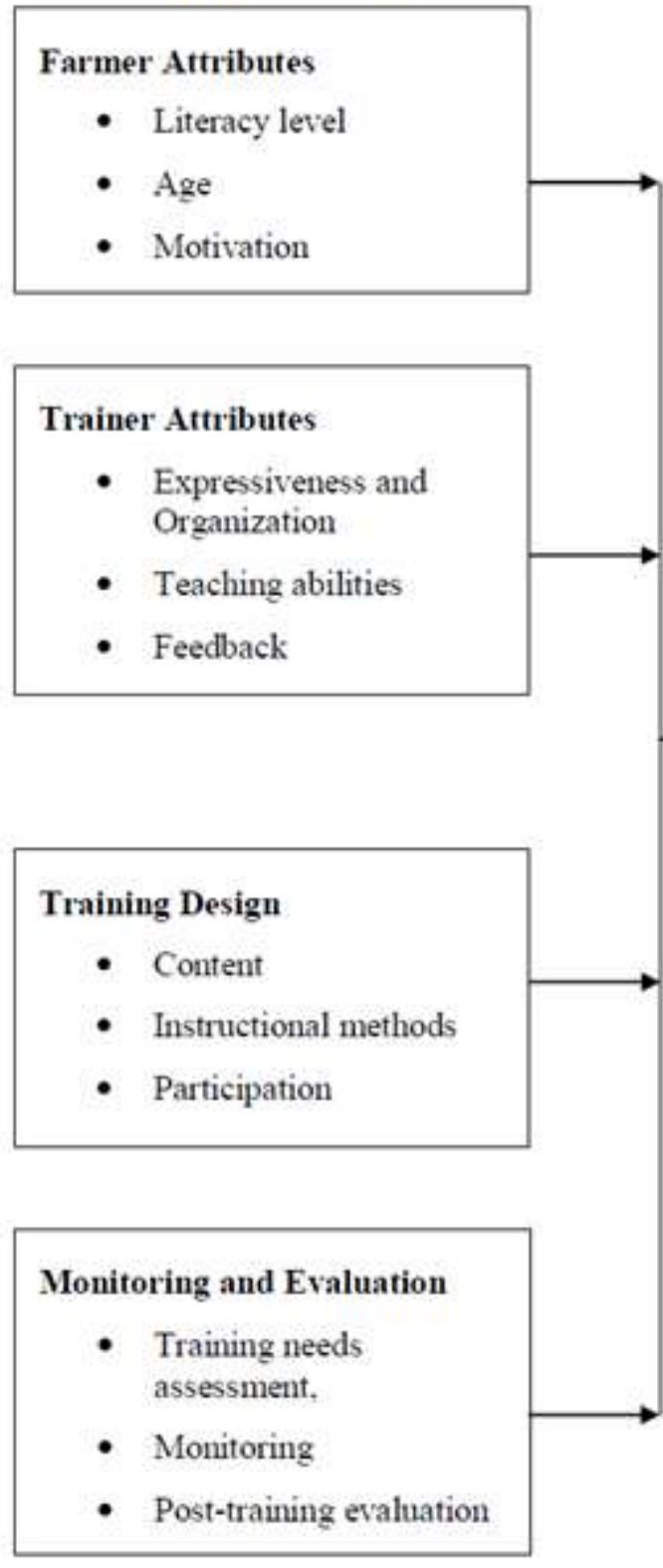

Moderating Variables

Learning-Transfer Environment

- Land tenancy

- Material support

- Gender

- Incentives

Figure1: Conceptual framework on factors training in transfer of $A B P$. 
The conceptual framework shows that the level of transfer of agricultural best practices is influenced by trainee attributes, trainer attributes, training design and monitoring and evaluation of the training programme. The attributes of the trainee covers such distinguishing characteristics as motivation to train and transfer, age and level of literacy. Trainer attributes cover such distinguishing characteristics such as expressiveness and organization, teaching abilities and feedback. Training design has issues as content, instructional methods and participation. Monitoring and evaluation covers issues such as training needs assessment, routine monitoring and post training evaluation.

\section{RESEARCH GAP}

There has been almost no study conducted specifically for the Kilifi County as far as training transfer for the farmers is concerned. While many studies have been conducted on training transfer a number of them have studied trainee attributes, transfer design and transfer environment-the likes of Yamhill \& McLean (2001); Curry, Caplan \& Knuppel (1994) and Salas \& Cannon-Bowers (2001). Only few like Kirkpatrick (1979) studied monitoring and evaluation singly as another important factor in transfer. Most of these studies researched on monitoring and evaluation only did some aspects of it under either trainer attributes or the training design. For example Boendermaker et al., (2003) found feedback as a factor under trainer's teaching skills. Salas \& Cannon-Bowers (2001) found the importance of needs assessment under the training design component. In this study the intention was to come up with a new model of approaching training by looking at the four aspects namely: trainee attributes, trainer attributes, training design and monitoring and evaluation. Learning-transfer environment was treated as moderating variables which in the above previous studies they were treated as independent variables.

\section{LITERATURE REVIEW SUMMARY}

From the analysis above it is clear that training is a very important component in building the capacity of the targeted population. Training improves performance and productivity but what counts in every training program is whether the participants are able to grasp and apply the skills they learn to their work. Various researchers have classified various factors affecting transfer of training into various categories: training inputs, (including trainee characteristics, training design, and work environment); training outputs, (consisting of learning and retention); and conditions of transfer depending on how each of them viewed such components.

\section{RESEARCH Methodology}

\subsection{Research Design}

A research design is the strategy for a study and the plan by which the strategy is to be carried out. It specifies the methods and procedures for the collection, measurement, and analysis of data (Mwanyota, n.d.).

The study used a descriptive survey design. According to Kothari (2004) the design provides a deep understanding of the circumstances under study and its instruments are helpful in getting in-depth first hand experiences; and that it has ability to allow the collection a large amount of data quickly and a minimal cost. It is concerned with conditions that exist, practices that prevail, beliefs and attitudes that are held, processes that are ongoing and the trends that are developing.

\subsection{Target Population}

The target population of the study was 149 working in the Gandini irrigation Project in Gandini sublocation of Bungale location, Magarini sub-county in Kilifi County (KRCS, 2014). This figure was arrived at by the six blocks A, B, C, D, E and F. Blocks A, B, C and D border each other as they are found in one nuclear plot in Lukole village of Gandini sub-location while blocks $\mathrm{E}$ and $\mathrm{F}$ border each other but found in Kwandezi village of the same sub-location.

\subsection{Sampling Procedure and Sample Size}

Since each of the six blocks had varied number of farmers the research adopted random sampling method of proportionate stratified sampling procedure. According to Bordens \& Abbott (2011) in random sampling, every member of the population has an equal chance of appearing in the sample; it eliminates the possibility that the sample is biased by the preferences of the person selecting the 
sample and affords some assurance that the sample does not bias itself. The proportionate stratified sampling ensures the degree of representativeness and leads to an equal representation of each segment (in this case the blocks) of the population sample.

The sample size of the study was 108 farmers calculated using the formula and table by Krejcie \& Morgan (1970).

This was about 72 percent of the total farmers. Each of the 6 blocks had $72 \%$ of the farmers taking part in the survey.

\subsection{Data Collection Methods}

Questionnaires with structured and semi-structured questions were administered to 108 sampled farmers to collect quantitative data. Focus Group Discussions (FGDs) were overseen (using FGD guides) to two groups (6 men and 6 women) to collect qualitative data. A checklist was used to collect quantitative data about the project. Secondary data was collected from the reports from the implementing agency (KRCS, Malindi Branch). The quantitative and qualitative data was used for triangulation.

\subsection{Data Collection Procedure}

The researcher trained the four ( 2 male and 2 females) research assistants on how to collect the data using the tools (questionnaires, FGD guide and check lists) that had already been prepared. After which data was collected and verified in 5 days.

\subsection{Validity of the Research Instruments}

Gakuu \& Kidombo (2010) refers validity to the appropriateness, meaningfulness and usefulness of the inferences a researcher makes (drawing the correct conclusions based on the data obtained from an assessment). To ensure content related validity; the questions were set in a form that they were appropriate, comprehensive to obtain information to enable measure most of (if not all) the constructs of the variables; criterion related validity, the formulated questions that were relevant, free from bias so that the information that was being sought was availed by the respondents. Piloting was done was done using 12 questionnaires. They were found to be valid.

\subsection{Reliability of the Research Instruments}

Bordens \& Abbott (2011) define reliability as ability to produce similar results when repeated measurements are made under identical conditions while Gakuu \& Kidombo (2010) define it as the degree of consistency of score or answers from one administration of an instrument to another, and from one set of items to another. Reliability was guaranteed by training and using motivated research assistants to conduct the research and also by broadening the sample by increasing the sample size from the least 10 percent as suggested by Mugenda \& Mugenda (1999) to 72.5 percent (that is 108 out of 149). The researcher carried out test retests to the 10 percent of the sample (that is 11 respondents) and analyze by correlation coefficient. The Pearson's coefficient was 0.98025 as the Spearman Brown's coefficient was 0.99003 .

\subsection{Ethical Considerations}

To successfully conduct this study the researcher submitted a written request to KRCS Malindi for permission to study Gandini Irrigation Project which was replied in writing (permission letter). The consent was sought from all the participants before any data would be collected from them; and the purpose of the study was explained comprehensively to them. Their confidentiality was assured. None of them his or her name or identity was captured on the questionnaire. Data was not interpreted from a biased perspective.

\subsection{Data Analysis Techniques}

In data analysis, computation of certain measures along with the searching for patterns of relationship that exist among data groups was done as drawn from Kothari's (2004) definition. To investigate whether a dependence relationship exists between two variables or whether the variables are statistically independent a Chi-square was used in testing the hypotheses. The qualitative data collected from the FGDs, analyzed and presented for triangulation with the quantitative data that was collected using the checklist and questionnaires. Cross tabulation was used as well as determination of correlation among the variables. 
Influence of Training Programme on the Transfer Level of Agricultural Best Practices by Farmers: A Case of Gandini Irrigation Project, Kilifi County Kenya

\section{FINDINGS}

\subsection{General Information of the Respondents}

This section sought to find the general information about the respondents including: gender, age, level of education and marital status. This section also sought to find out the mode of acquisition of the plot on which they work and whether they had ever attended any agriculture best practice training organized for the farmers within Gandini Irrigation Project.

Table4.1. Summary of demographic information

\begin{tabular}{|l|l|l|l|}
\hline Demography & Respondents & Total & Percentage \\
\hline Gender & Male & 24 & 22.43 \\
\hline Age & Female & 83 & 77.57 \\
\hline & $18-35$ years & 36 & 33.64 \\
\hline & $36-55$ years & 55 & 51.40 \\
\hline Marital status & Above 55 years & 16 & 14.95 \\
\hline & Single & 3 & 2.80 \\
\hline & Married & 92 & 85.98 \\
\hline & Single parent & 2 & 1.87 \\
\hline & Widowed & 9 & 8.41 \\
\hline Level of education & Divorced & 1 & 0.93 \\
\hline & Did not attend school & 58 & 54.21 \\
\hline & Lower primary school & 7 & 6.54 \\
\hline & Upper Primary school & 35 & 32.71 \\
\hline & Secondary school & 6 & 5.61 \\
\hline Land tenure & Tertiary college & 1 & 0.93 \\
\hline & Bought & 22 & 20.56 \\
\hline & Rented & 39 & 36.45 \\
\hline Training attendance & Family land & 46 & 42.99 \\
\hline & No & 1 & 0.93 \\
\hline
\end{tabular}

The study recorded $100 \%$ response rate. More than three quarters $(77.58 \%)$ of the farmers in GIP were female as male farmers were slightly less than a quarter $(22.43 \%)$. Two thirds of the farmers were out of the youth bracket (beyond 35 years); only a third of the farmers were in the youth bracket though the larger percentage (almost all) have family responsibilities (97.20\%). More than have of the population (of farmers) did not go to school; $39.25 \%$ attended various levels of primary education; and only $6.54 \%$ attended school beyond primary school. More than a half $(53 \%)$ of the population do not own land in the irrigation schemes and only $43 \%$ work on family land (but not entirely owning it). 99\% had attended training in the last one year.

\subsection{Trainee Attributes and the Transfer of Agriculture Best Practices by Farmers in Gandini Irrigation Project}

This variable was aimed at establishing the extent to which trainee attribute influence the level of transfer of agriculture best practices by farmers. It was examined using three key indicators namely: trainee motivation, age and level of literacy. Motivation was assessed by attendance to the training against the worth of attending; age was assessed by the recall of main topics while literacy was assessed by the ability to read and use or apply the information from the training.

In responding to the statement 'Attending a farmer's training is as good as not attending one' in determining the motivation, 31 farmers $(28.97 \%)$ agreed while 76 farmers $(71.03 \%)$ disagreed while 1 farmer (1\%) farmer was undecided. On age versus recall: 102 farmers (95.33\%) agreed that they remembered the main topics or relevant concepts that were taught during the previous trainings while2 farmers (1.87\%) disagreed as 3 farmers $(2.80 \%)$ were undecided. The literacy level was measured by finding out whether the farmers were able to read and use what they had learned from the previous trainings. The 66 farmers $(61.68 \%)$ agreed; 39 farmers $(36.45 \%)$ disagreed while 2 farmers $(1.87 \%)$ were undecided. These two were of age above 55 years. 
Influence of Training Programme on the Transfer Level of Agricultural Best Practices by Farmers: A Case of Gandini Irrigation Project, Kilifi County Kenya

Table4.2. Top 10 out of 26 topics or concepts that the farmers remembered

\begin{tabular}{|l|l|l|l|}
\hline SNo & Topic/Concept & Score & $\%$ \\
\hline 1 & Land preparation (basin preparation) & 56 & 21.46 \\
\hline 2 & Maize planting (seed/hole) & 40 & 15.33 \\
\hline 3 & Nursery preparation & 35 & 13.41 \\
\hline 4 & Chemical spraying & 21 & 8.05 \\
\hline 5 & Intercropping & 20 & 7.66 \\
\hline 6 & Tomato culture & 15 & 5.75 \\
\hline 7 & Fertilizer /manure application & 11 & 4.21 \\
\hline 8 & Value addition (tomato jam/cassava milling & 09 & 3.45 \\
\hline 9 & Cooperative management & 08 & 3.07 \\
\hline 10 & Hygiene and nutrition & 08 & 3.07 \\
\hline
\end{tabular}

Presentation of the hypothesis testing between the trainees attributes and level of transfer of agriculture best practices by farmers in Gandini Irrigation Project is as follows:

$\mathbf{H}_{0}$ : The trainee attributes in a training programme influence the level of transfer of agricultural best practices in Gandini Irrigation Project

$\mathbf{H}_{1}$ : The trainee attributes in a training programme do not influence the level of transfer of agricultural best practices in Gandini Irrigation Project

Table4.3. Chi-square results on the relationship between trainee attributes and level of transfer of agriculture best practices

\begin{tabular}{|l|l|l|l|l|}
\hline & Chi-square value & d.f. & X -Table value & Decision on null \\
\hline Motivation & 4.1339 & 4 & 9.488 & Rejected \\
\hline Age & 14.837 & 8 & 18.307 & Rejected \\
\hline Literacy level & 60.9855 & 16 & 26.296 & Accepted \\
\hline
\end{tabular}

The null hypothesis for motivation was rejected. The null hypothesis for age was also rejected while null hypothesis for literacy was accepted.

\subsection{Trainer Attributes and the Transfer of Agriculture Best Practices by Farmers in Gandini Irrigation Project}

This variable was aimed at establishing the extent to which trainer attribute influence the level of transfer of agriculture best practices by farmers. It sought to find out whether the trainees perceived any differences among the trainers who have trained them in the past. It was examined using three key indicators namely: trainer expressiveness and organization; trainer teaching abilities; and feedback from the trainer. Expressiveness and organization was assessed by perception of trainees in relation to boredom; trainer teaching abilities was assessed by the language used. The responses by the farmers as per the three indicators are as shown in the following tables.

Slightly above a fifth $(21.50 \%)$ of the farmers (that is 23 farmers) agreed that the trainers showed some level of differences in their way of training while the rest, 84 (78.50\%) farmers perceived no difference among the trainers. Only 3 farmers $(2.60 \%)$ agreed that they were bored with the way the trainers taught their material to them while 103 farmers $(96.26 \%)$ disagreed while 1 farmer $(0.94 \%)$ was undecided. 29 farmers (27.10\%) agreed that sometimes information passed them because of the language used during the previous trainings while 68 farmers $(63.55 \%)$ disagreed as 10 farmers (9.35\%) were undecided. With feedback 38 farmers (35.51\%) agreed; 53 farmers $(49.53 \%)$ disagreed while 16 farmers $(14.95 \%)$ were undecided.

The following hypothesis was tested under the study.

$\mathbf{H}_{\mathbf{0}}$ : The trainer attributes in a training programme influence the level of transfer of agricultural best practices in Gandini Irrigation Project

$\mathbf{H}_{1}$ : The trainer attributes in a training programme do not influence the level of transfer of agricultural best practices in Gandini Irrigation Project 
Influence of Training Programme on the Transfer Level of Agricultural Best Practices by Farmers: A Case of Gandini Irrigation Project, Kilifi County Kenya

Table4.4. Chi-square results on the relationship between trainer attributes and level of transfer of training of agriculture best practices

\begin{tabular}{|l|l|l|l|l|l|}
\hline & Chi-square value & d.f. & X -Table value & & Decision \\
\hline Expressiveness and organization & 4.9939 & 4 & 9.488 & & Rejected \\
\hline Teaching abilities (language) & 6.5334 & 4 & 9.488 & Rejected \\
\hline Feedback & 12.4562 & 4 & 9.488 & Accepted \\
\hline
\end{tabular}

\subsection{Training Design and the Transfer of Agriculture Best Practices by Farmers in Gandini Irrigation Project}

This variable was aimed at establishing the extent to which training design influences the level of transfer of agriculture best practices by farmers. It sought to find out what the trainees perceived (liking) about the design. It was examined using three key indicators namely: content; instructional methods; and participation by the trainees. The content was assessed against the relevancy (usefulness) instructional methods were assessed against its applicability in the presentation of the material (information); while participation against chance by farmers (trainees) to fully participate during the training.

Almost all the farmers (99 farmers, 92.52\%) liked the manner in which the previous trainings had been conducted. Only 8 farmers $(7.48 \%)$ had disagreed. With content relevancy only 8 farmers (7.48\%) agreed that sometimes they got information that is not useful while 92 farmers $(85.98 \%)$ disagreed while 7 farmers (6.54\%) were undecided. 101 farmers (94.39\%) agreed that methods that the trainers used to present the materials were applicable during the previous trainings while 4 farmers $(3.74 \%)$ disagreed as 2 farmers $(1.87 \%)$ were undecided on instructional methods. With participation 87 farmers (77.57\%) agreed; 17 farmers (15.89\%) disagreed while 7 farmers (6.54\%) were undecided. Presentation of the hypothesis testing between the trainees attributes and level of transfer of agriculture best practices by farmers in Gandini Irrigation Project is as follows:

$\mathbf{H}_{\mathbf{0}}$ : The training design in a training programme influence the level of transfer of agricultural best practices in Gandini Irrigation Project

$\mathbf{H}_{1}$ : The training design in a training programme does not influence the level of transfer of agricultural best practices in Gandini Irrigation Project

Table4.5. Chi-square results on the relationship between training design and level of transfer of training of agriculture best practices

\begin{tabular}{|l|l|l|l|l|}
\hline & Chi-square value & d.f. & X -Table value & Decision on null \\
\hline Content relevancy & 3.16086 & 4 & 9.488 & Rejected \\
\hline Instructional methods & 17.1440 & 4 & 9.488 & Accepted \\
\hline Participation & 47.8000 & 4 & 9.488 & Accepted \\
\hline
\end{tabular}

Another relationship emerged and the researcher sought to find the relationship between the training design (applicability of instructional methods) and the trainer attributes (age and level of literacy).

Based on literacy level and age vis-à-vis instructional methods, six farmers (5.61\%) did not agree with the statement 'the methods that the trainer(s) used to present the material were applicable' while 101 farmers (94.39\%) agreed with the statement.

Table4.6. Chi-square results on the relationship between training design (instructional methods and trainee age and level of literacy in respect to transfer of agriculture best practices

\begin{tabular}{|l|l|l|l|l|}
\hline & Chi-square value & d.f. & X-table value & Decision on null \\
\hline Age & 8.101148 & 8 & 18.307 & Rejected \\
\hline Level of literacy & 36.1339247 & 16 & 26.296 & Accepted \\
\hline
\end{tabular}

\subsection{Monitoring and Evaluation and the Transfer of Agriculture Best Practices by Farmers in Gandini Irrigation Project}

This variable was aimed at assessing the extent to which monitoring and evaluation influences the level of transfer of agriculture best practices by farmers. It was examined using three key indicators namely: training needs assessment (need driven training); monitoring; and post training evaluation. The study sought to know whether farmers had ever been asked what they needed to be trained in vs. need driven training; whether they had ever been visited by trainers (extension officers) and discuss 
the progress and whether there was any need to change training mode against the benefits of the training.

Less than half of the farmers, 49 farmers (45.79\%) agreed that they had ever been asked what they needed to be trained about while more than half, 58 farmers $(54.21 \%)$ had disagreed, though 100 farmers $(93.46 \%)$ agreed that the trainings just came at the right time when I needed them while only 6 farmers $(5.61 \%)$ disagreed as 1 farmer $(0.94 \%)$ was undecided. Around two thirds of the farmers, 70 farmers (65.42) agreed that the trainer had ever visited their plots to see how you were progressing while about a third, 37 farmers $(34.58 \%)$ refused. Out of this72 farmers $(67.29 \%)$ agreed that trainer had met with them to discuss ways to apply training on the farm while 34 farmers $(31.78 \%)$ disagreed as only1 farmer $(0.94 \%)$ was undecided. On post training evaluation 38 farmers $(35.51 \%)$ thought that the way the trainings had been conducted should be changed while 69 farmers (64.49\%) thought it should not be changed. Almost all the farmers, 104 farmers $(97.19 \%)$ claimed that they had started realizing the benefit of the trainings while only 2 farmers (1.87\%) had not as 1 farmer was undecided.

The following is a presentation of the hypothesis test between the monitoring and evaluation and level of transfer of agriculture best practices by farmers in Gandini Irrigation Project.

$\mathbf{H}_{\mathbf{0}}$ : Monitoring and evaluation in a training programme influence the level of transfer of agricultural best practices in Gandini Irrigation Project

$\mathbf{H}_{1}$ : Monitoring and evaluation in a training programme do not influence the level of transfer of agricultural best practices in Gandini Irrigation Project

Table4.7. Chi-square results on the relationship between Monitoring and evaluation and level of transfer of training of agriculture best practices

\begin{tabular}{|l|l|l|l|l|}
\hline & Chi-square value & d.f. & X -Table value & Decision on null \\
\hline Training needs assessment & 11.4733 & 4 & 9.488 & Accept \\
\hline Monitoring & 98.4081 & 4 & 9.488 & Accept \\
\hline Post training evaluation & 2.98392 & 4 & 9.488 & Reject \\
\hline
\end{tabular}

The null hypothesis for indicator 'training needs assessment and monitoring' were accepted since at 4 degrees of freedom the calculated Chi-square values (11.4733 and 98.4081) are than Chi-square table value (9.488). Since at 4 degrees of freedom the calculated Chi-square values for 'post training evaluation' (2.98392) is less than Chi-square table value (9.488), the null are therefore rejected.

\subsection{FGD Results on the influence of training on transfer of agriculture best practices by farmers in Gandini Irrigation Project}

From the FGDs the respondents confirmed that indeed the level of education played an important level of training transfer. Education came in especially in reference to the use of chemical sprays which a farmer needs to read the labels; and understanding the 'foreign language-English' used during the training. Farmer mentioned the trainee attributes as level of education, family responsibilities (confirmed as $97.20 \%$ having family responsibilities and $77.58 \%$ are women), gender, age, motivation (they cited incentives), and culture in that order.

The respondents when asked who a good teacher (trainer) they listed the attributes in the order of ability to use a language understandable by the trainer, respects the opinion of the trainee; gives feedback (asking questions to find out whether the trainees understand; lowers to the level of the trainee (humility); does not show any form of favouritism; in between harsh and polite and able to use working example. This confirms the chi-square results for feedback $\left(X^{2}=12.4562\right)$.

All the respondents in the FGDs expressed satisfaction of the way the trainings had been conducted however they mentioned that the most successful training and its transfer would be reached if trainers came in mixed genders; a design is more practical (participatory which is confirmed by Chi-square value, $X^{2}=47.8000$ ) than theoretical; appropriate session timing (confirming the trainee responsibilities and the importance of training needs assessment that had a Chi-square value $X^{2}=11.4733$ ); trainings couple with exposure trainings; and venue sensitive so as not to divert training attention to family matters during training (such as children asking for parents attention). The respondents also noted that the trainers should appreciate that the trainees have different levels of literacy and therefore when choosing a design they should be very keen on meeting each trainees level. The higher liking score was confirmed also by the Chi-square value $X^{2}=17.1440$. 
The respondents affirmed that their involvement in monitoring and evaluation deepens their learning and understanding and an opportunity to undertake any corrective measure in the event they go astray in the application of the skills they acquire. This confirms the Chi-square value, $X^{2}=98.4081$. The respondents also mentioned that their role as trainees was coming up with suggestions of important areas of concern during the trainings, listening and participation during the training and farmer to farmer sharing and refreshing after the training.

Even after liking the trainings the respondents mentioned financial and physical capability (money and energy required to execute some of practices); low levels of education; size and security of the plots; limited extension services by trainers; attitude towards change from subsistence to agri-business approach of crop production; and fear of dangers of some farming techniques (dangers of chemicals) as most factors impeding the successful transfer of training.

\section{CONCLUSION}

The transfer of agricultural best practices is influenced by the trainee attributes, trainer attributes, training design and monitoring and evaluation. Trainee (farmer) attributes such as level of literacy, family responsibilities, gender, age, motivation (they cited incentives), and culture were found important. Ability of the trainer to give and get feedback from the farmers is essential for the learners' growth as it provides direction and helps to boost confidence. Any training design should keep in mind the participatory approach and instructional methods that teach the general rules and theoretical principles that underlie the training content there results a positive influence training transfer by providing learning experiences in different ways. Undertaking training needs assessment helps in specifying the learning objectives, which in turn shape the design and delivery of training; monitoring tracks the progress of applying learners' newly learned skills and reinforce knowledge while evaluation provide information that is credible and useful, enabling the incorporation of lessons learned into the decision-making process and celebrating of accomplishments.

\section{RECOMMENDATIONS}

The project team should thoroughly consider training needs assessment so as shape the design and delivery of training and meet each trainee objectives during and after training. Use of exchange programmes and establishment farmer field schools for exposure and exchange of ideas and experiences aimed at in-depth understanding of all-round project management concepts at the community level. The project implementers should initiate and invest in Trainer of Trainees (ToT) approach so as encourage lateral training and monitoring and evaluation in the event that the government extension officers are overwhelmed due to wider geographical coverage.

\section{RECOMMENDATIONS FOR FURTHER STUDIES}

Emanating from the findings, the study recommends to study: the influence of culture on the trainee on the influence of agricultural best practices in irrigation projects; and influence of land tenancy on the influence of agricultural best practices in irrigation projects

\section{REFERENCES}

[1] ACF International (2009). Food Security and Livelihood Assessments: A Practical Guide for Field Workers.

[2] Agnes C. Rolaand Serlie B. Jamias, Jaime B. Quizon (2002). Do Farmer Field School Graduates Retain and Share What They Learn?: An Investigation in Iloilo, Philippines. Journal of International Agricultural and Extension Education (Vol 9, No. 1)

[3] Barton, P. E. (2000). What Jobs Require: Literacy, Education, and Training, 1940-2006. Policy Information Report. Accessed from ed.gov

[4] Boendermaker, P. M., Conradi, M. H., Schuling, J., Meyboom-de Jong, B., Zwierstra, R. P., \& Metz, J. C. (2003). Core Characteristics of the Competent General Practice Trainer, A Delphi Study. Advances in Health Sciences Education, 8(2), 111-116.

[5] Boendermaker, P. M., Schuling, J., Meyboom-de Jong, B., Zwierstra, R. P., \& Metz, J. C. (2000). What Are The Characteristics of The Competent General Practitioner Trainer?. Family practice, 17(6), 547-553.

[6] Bordens, K. S., \& Abbott, B. B. (2011).Research Design and Methods: A Process Approach (8th ed.). Mountain View, CA: Mayfield.

[7] Burke, L. A., \& Hutchins, H. M. (2008). A study of best practices in training transfer and proposed model of transfer. Human Resource Development Quarterly, 19(2), 107-128. 
Influence of Training Programme on the Transfer Level of Agricultural Best Practices by Farmers: A Case of Gandini Irrigation Project, Kilifi County Kenya

[8] Byerlee, D., Diao, X., \& Jackson, C. (2005). Agriculture, Rural Development, and Pro-Poor Growth: Country Experiences In The Post-Reform Era. Agriculture and Rural Development Discussion Paper, 21, 1-7. Accessed at worldbank.org on 27/01/2015.

[9] Clynes, M. P., \& Raftery, S. E. (2008). Feedback: An Essential Element of Student Learning In Clinical Practice. Nurse Education in Practice, 8(6), 405-41. Accessed from nbu.bg on 12/02/2015.

[10] Colquitt, J. A., LePine, J. A., \& Noe, R. A. (2000). Toward An Integrative Theory of Training Motivation: A Meta-Analytic Path Analysis of 20 Years of Research. Journal of applied psychology, 85(5), 678.Accessed from rice.edu

[11] Curry, D. H., Caplan, P., \& Knuppel, J. (1994). Transfer of Training and Adult Learning (TOTAL). Journal of Continuing Social Work Education, 6(1), 8-14.

[12] Dalsgaard, J. P. T., Minh, T. T., Giang, V. N., \& Riise, J. C. (2005). Introducing a Farmers' Livestock School Training Approach into the National Extension System in Vietnam. Overseas development institute (ODI).

[13] Davis, K., Franzel, S., Hildebrand, P., Irani, T., \& Place, N. (2004). Extending technologies among smallscale farmers in Meru, Kenya: Ingredients for Success in Farmer Groups. The Journal of agricultural education and extension, 10(2), 53-62.

[14] De Janvry, A. (2010). Agriculture For Development: New Paradigm and Options for Success. Journal of Agricultural Economics, 41(s1), 17-36.

[15] FAO (2011). The State of Food Insecurity in the World: How Does International Price Volatility Affect Domestic Economies and Food Security?.Rome

[16] FAO (2013). The State Of Food and Agriculture: Food Systems for Better Nutrition. Rome

[17] FAO (2005). Protecting and Promoting Good Nutrition in Crisis And Recovery: Resource Guide. Rome

[18] Feder, G., Murgai, R., \& Quizon, J. B. (2004). The Acquisition And Diffusion Of Knowledge: The Case Of Pest Management Training In Farmer Field Schools, Indonesia. Journal of agricultural economics, 55(2), 221-243.

[19] Ford, J. K., \& Weissbein, D. A. (1997). Transfer of Training: An Updated Review and Analysis. Performance improvement quarterly, 10(2), 22-41.

[20] Gakuu C. M \& Kidombo, H.J (2010) LDP 603: Research Methods. University of Nairobi.

[21] Godtland, E. M., Sadoulet, E., De Janvry, A., Murgai, R., \& Ortiz, O. (2003). The Impact of Farmer Field Schools On Knowledge And Productivity: A Study Of Potato Farmers In The Peruvian Andes. Economic development and cultural change, 53(1), 63-92.

[22] Gollin, D., Parente, S., \& Rogerson, R. (2002). The Role of Agriculture in Development. American Economic Review, 160-164.

[23] IFRC\&RCS (2011). Project/Programme Monitoring and Evaluation (M\&E) Guide

[24] Irby, D.M. (1995). Teaching And Learning In Ambulatory Care Settings: A Thematic Review Of The Literature. Academic Medicine 70: 898-931.

[25] Kilifi County financial plan (2014). Ministry of Agriculture, Livestock and Fisheries Estimates

[26] Kilpatrick, S. (2000). Education and Training: Impacts on Farm Management Practice. The Journal of Agricultural Education And Extension, 7(2), 105-116.

[27] Kirkpatrick, D. L. (1979). Techniques for Evaluating Training. Training \& Development Journal, 33(6), 78-92.

[28] Kothari, C.R. (2009). Research Methodology: Methods and Techniques. New Age International (P) Ltd Publishers.

[29] KRCS (2014). Kilifi County Annual Report. Narrative Financial report.

[30] Krejcie, R. V., \& Morgan, D. W. (1970). Determining sample size for research activities.

[31] Educational And Psychological Measurement 30: 607-610

[32] Kubeck, J. E., Delp, N. D., Haslett, T. K., \& McDaniel, M. A. (1996). Does Job-Related Training Performance Decline With Age?. Psychology and Aging, 11(1), 92.

[33] Lim, D. H. (2000). Training Design Factors Influencing Transfer Of Training To The Workplace Within An International Context. Journal of Vocational Education and Training, 52(2), 243-258.

[34] Mwanyota, J.L. (n.d.). Business Research Methodology. University of Nairobi

[35] Mugenda, A. \& Mugenda O. (1999). Research Methods: Qualitative and Quantitative Approaches, Nairobi: Acts Press.

[36] Nikandrou, I., Brinia, V., \& Bereri, E. (2009). Trainee Perceptions of Training Transfer: An Empirical Analysis. Journal of European Industrial Training, 33(3), 255-270.

[37] Paul, S. (1987). Community Participation in Development Projects. Washington, DC: World Bank.

[38] Pretty, J. N. (1995). Participatory learning for sustainable agriculture. World development, 23(8), 12471263.

[39] Richardson, S. (2004). Employers' contribution to training. Adelaide, SA, Australia: NCVER.

[40] Rola, A. C., Jamias, S. B., \& Quizon, J. B. (2002). Do Farmer Field School Graduates Retain And Share What They Learn? An investigation in Iloilo, Philippines. In Farmer field schools: Emerging issues and 
Influence of Training Programme on the Transfer Level of Agricultural Best Practices by Farmers: A Case of Gandini Irrigation Project, Kilifi County Kenya

challenges. International Learning Workshop on Farmer Field Schools (FFS). Yogyakarta (Indonesia). 21 25 Oct 2002. (p. 261). International Potato Center.

[41] Salas, E., \& Cannon-Bowers, J. A. (2001). The Science of Training: A Decade of Progress. Annual Review of Psychology, 52(1), 471-499.

[42] Salas, E., Tannenbaum, S. I., Kraiger, K., \& Smith-Jentsch, K. A. (2012). The science of training and development in organizations: What matters in practice. Psychological science in the public interest, 13(2), 74-101.

[43] Schwartz, R. C. (1988). The trainer-trainee relationship in family therapy training. Handbook of family therapy training and supervision, 172-182. Pp 174

[44] Seyler, D. L., Holton III, E. F., Bates, R. A., Burnett, M. F., \& Carvalho, M. A. (1998). Factors affecting motivation to transfer training. International Journal of Training and development, 2(1), 16-16.

[45] Shoenfelt, E. L. (1991). The Relative Effectiveness of Training Methods for Attaining Training Objectives: Current Opinion of Training Practitioners.

[46] Stewart, P., Danford, A., Richardson, M., \& Pulignano, V. (2010). Workers' experiences of skill, training and participation in lean and high performance workplaces in Britain and Italy. Employee Relations, 32(6), 606-624.

[47] Swanson, B. E. (2008). Global Review of Good Agricultural Extension and Advisory Service Practices. Food and Agriculture Organization of the United Nations.

[48] Towler, A. J., \& Dipboye, R. L. (2001). Effects of trainer expressiveness, organization, and trainee goal orientation on training outcomes. Journal of Applied Psychology, 86(4), 664.

[49] Umrani, F., \& Ghadially, R. (2003). Empowering women through ICT education: Facilitating computer transfer. Gender, Technology and Development, 7(3), 359-377

[50] Van Gerven, P. W. M., Paas, F. G. W. C., Van Merriënboer, J. J. G., \& Schmidt, H. G. (2002). Cognitive load theory and aging: Effects of worked examples on training efficiency. Learning and Instruction, 12(1), 87-105

[51] Velada, R., Caetano, A., Michel, J. W., Lyons, B. D., \& Kavanagh, M. J. (2007). The effects of training design, individual characteristics and work environment on transfer of training. International Journal of Training and Development, 11(4), 282-294.

[52] WFP. (2014). Global Food Security Update: Tracking Food Security Trends In Vulnerable Countries, 16.

[53] World Bank (2015). Millennium Development Goals. From: http://www.worldbank.org/mdgs/poverty_ hunger.html accessed on 5/2/2015

AUTHORS' BIOGRAPHY

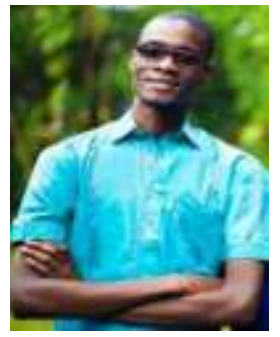

Cornel Likale Ndombi, Project officer for the last six years, with Kenya Red Cross Society, department of Disaster Risk Management with strong affinity to community participation and capacity building. Lecturer, University of Nairobi, Malindi Learning Centre, Department of Open Distance Learning, School of Open Distance and Distance Learning. Holds Bachelor's degree in Horticulture from Egerton University, Masters Degree in Project management and is a PhD student in Project Planning and Management specializing in Project Planning, Design and Implementation from University of Nairobi, Kenya. Research interests participatory planning and management

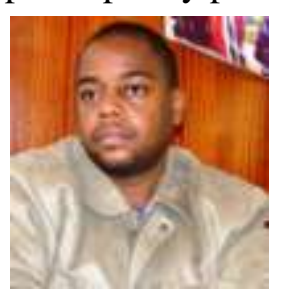

Johnbosco Kisimbii, Lecturer For The Last Seven Years, University of Nairobi Department of Open Distance Learning, School of Open and Distance Learning. Specialist in the following subjects at both Post-graduate and Undergraduate levels- Research Methods, Statistical Methods, Entrepreneurship and Small Business Management, Managerial Economics, Microeconomics and Macroeconomics, Quantitative Techniques, Economic Development and project management. Supervised several Master's Thesis in Project Planning and Management and Economics. Involved in Preparation of Curriculum and Development of Distance Learning Modules

Citation: Cornel Likale Ndombi and Johnbosco Kisimbii. "Influence of Training Programme on the Transfer Level of Agricultural Best Practices by Farmers: A Case of Gandini Irrigation Project, Kilifi County Kenya." International Journal of Managerial Studies and Research (IJMSR), vol 5, no. 10, 2017, pp. 30-47. doi:http://dx.doi.org/10.20431/2349-0349.0510004.

Copyright: (C) 2017 Authors. This is an open-access article distributed under the terms of the Creative Commons Attribution License, which permits unrestricted use, distribution, and reproduction in any medium, provided the original author and source are credited. 